\title{
Exclusive transabdominal trans-amniotic approach for chorionic villus sampling in posterior placenta: a novel approach for prenatal diagnosis of genetic disorders
}

\author{
B. I. Patel*, Saumil Patel, Nisha Patel
}

Consulting Obstetrics and Gynecologist, Gynob Sonoscan Center, Dev ART IVF- Test Tube Baby Center and Shachi women's Hospital, Ahmedabad, Gujarat, India

Received: 25 August 2021

Accepted: 07 September 2021

*Correspondence:

Dr. B. I. Patel,

E-mail: bipatel1@hotmail.com

Copyright: ( ) the author(s), publisher and licensee Medip Academy. This is an open-access article distributed under the terms of the Creative Commons Attribution Non-Commercial License, which permits unrestricted non-commercial use, distribution, and reproduction in any medium, provided the original work is properly cited.

\section{ABSTRACT}

Background: The objective of the study was to evaluate role and safety of transabdominal trans-amniotic approach for Chorionic villus sampling (CVS) for prenatal diagnosis of genetic disorders.

Methods: Retrospective analytical study carried out on data form couples coming for pre-natal diagnosis from January 2010 to February 2021. Patient related parameters like age, gestational age; procedure related parameters like amount of sample, number of attempts required; different genetic disorder diagnosed and complications by both the approaches of CVS were recorded and analyzed.

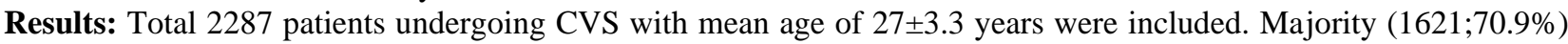
had CVS procedure at gestational age of 12-14 weeks. On analyzing physician's perception, 663 (29\%) patients having complete posterior placenta could not be accessible with routine trans-abdominal CVS and opted for trans-amniotic approach. Amount of sample yield and number of attempts were not statistically significant ( $>0.05)$ by both methods of CVS. Thalassemia major was found in 948 (41.45\%) followed by thalassemia minor in $525(22.96 \%)$ patients. No statistically significant difference was found for developing complications by both the methods ( $\mathrm{p}>0.05)$. Most common complication was pain and discomfort which was relieved by simple analgesics. Out of total 17 (0.74\%) abortions; 13 $(0.80 \%)$ from routine transabdominal and $4(0.60 \%)$ from trans-amniotic route CVS with no statistically significant difference among them $(\mathrm{p}>0.05)$. No case of post procedure infection was observed.

Conclusions: In complete posterior placenta CVS procedures usually postponed by most physicians leading to delay in diagnosis of genetic disorders. The novel method transabdominal trans-amniotic approach for CVS is effective and safe in skilled hands and can help in early prenatal diagnosis of genetic disorders.

Keywords: Chorion villous sampling, Posterior placenta, Transabdominal CVS, Trans-amniotic CVS, Prenatal diagnosis, Genetic disorders

\section{INTRODUCTION}

Prenatal diagnosis of genetic disorders has been increasingly used in clinical practice now-a-days. Prenatal diagnosis is offered to high risk patients of having risk of genetic disorders, family history of genetic disorders, age more than 35 years etc. Early prenatal diagnosis and early or in time termination of the affected pregnancies have become an important component of the management of genetic disorders like Thalassemia and Down's Syndrome. ${ }^{1,2}$ Fetal cells suitable for such genetic testing could be obtained from maternal blood which is still under development or pre-implantation embryos, which is possible with in vitro fertilization only, which is often not feasible. At present, only the analysis of fetal cells from amniotic fluid, placenta (chorionic villus tissue), or fetal blood can result in an accurate prenatal diagnosis. ${ }^{3}$ 
Amniocentesis, Chorion villous sampling, fetal Blood sampling are different techniques used for prenatal diagnosis. Though amniocentesis is commonly used and most accurate method of prenatal diagnosis, a major disadvantage of second trimester amniocentesis is that a final result is usually available only after 17 weeks' gestation. ${ }^{4}$ Such a long waiting period for a diagnosis can be very distressing for couples, particularly when most obstetricians are reluctant to offer a surgical termination late in pregnancy. Earlier options include chorionic villus sampling (CVS) and early amniocentesis. High-quality evidence supported second trimester amniocentesis as the procedure of first choice for testing from 15 weeks' gestation or later. When a test is required earlier than 15 weeks' gestation, low-quality to moderate-quality evidence suggested that transabdominal chorionic villus sampling could be considered the procedure of first choice, depending on the outcome of interest. ${ }^{5}$

Chorionic villus sampling was first described in China in the mid-1970s, and developed further in the Western world during the 1980s (China 1975). ${ }^{6}$ The procedure involves aspiration of placental tissue rather than amniotic fluid. Ultrasound guided aspiration can be performed using either percutaneous transabdominal, the transvaginal, or trans-cervical approach. Currently, the choice of the approach and the choice of instruments tend to be based upon the operator's personal preference. ${ }^{7}$ Chorionic villus sampling (CVS) is the gold standard invasive procedure for first trimester prenatal diagnosis. ${ }^{8}$ Moreover, rapid analytic techniques have significantly reduced the turnaround time between sampling and diagnosis. Transabdominal CVS is associated with a lower rate of procedure related miscarriage than trans-cervical CVS. In experienced hands CVS is a safe procedure with overall fetal loss rate of $0.5-1.5 \% . .^{9}$ Occasionally, transabdominal CVS is difficult because of an axial-retroverted uterus, posterior low-lying placenta with or without imposed bowel, presence of uterine myoma, etc. so alternative approaches are required. Posterior placenta is one of the difficult aspect in the CVS and most clinician have fear of using CVS for such patients. ${ }^{10}$ This study was planned with aim of evaluating safety and outcome of the novel transabdominal trans-amniotic approach for CVS in posterior placenta for prenatal diagnosis of the genetic disorders.

\section{METHODS}

Study type and setting: This was a retrospective analytical study performed on the prospectively collected data over 10 years' form couples coming for pre-natal diagnosis at Dr B I Patel ${ }^{\mathrm{TM}}$ Gynob sonoscan center, Ahmedabad, from January 2010 to February 2021.

\section{Inclusion criteria}

All patients coming for prenatal diagnosis for various genetic disorders were screened and those willing to give written informed consent were enrolled for the procedure.
Couples requesting the prenatal genetic diagnosis were the target population for this study.

\section{Exclusion criteria}

Those who have refused for consent of aspiration were excluded. Also twins or multi fetal pregnancy, past history of threaten abortion or sub chorionic or retro placental hematoma in on going pregnancy were excluded from the study.

\section{Study procedure}

Before the CVS procedure, couples were counseled about the indications, genetic risks, procedure risks and complications of sampling, other options, video demonstration of the procedure, errors in diagnosis and the termination of pregnancy if needed and its religious implications also. A written informed consent was obtained from all couples. Routine ante-natal checkup was carried out. Maternal blood group testing and Rhesus prophylaxis was also given as per guidelines for testing of women for their Rhesus status and for presence of alloantibodies before invasive procedures. ${ }^{11}$ As Rhesus prophylaxis has been strongly recommended after an invasive procedure in non-sensitized Rhesus-negative women with a Rhesus-positive partner (unless the fetus has been found to be Rhesus negative by cffDNA testing of mother), single intramuscular dose of anti-D antibodies in fixed preparation was used for such cases. A preliminary first trimester ultrasound scan was done to determine the fetal viability, gestational age, number of fetus, placental location and any other incidental findings that might impact on the procedure. Neural tube, nasal bone, NT screening for FTS and gross abnormalities were also assessed on this ultrasound. When the gestational age was between 11-14 weeks or more, CVS was carried out immediately. Physician's perception about selecting the route for CVS has also been taken into consideration and based on that CVS was performed by either routine tansabdominal method or newer technique transabdominal but trans-amniotic approach for CVS. ${ }^{12}$

\section{Trans-amniotic approach for CVS procedure}

The ultrasound scanning (USG) was done either on Voluson E8 radiance and V5 using a 5MHz convex probe. Placental position and thickness of placenta was ascertained and a suitable site for introducing the needle on the anterior abdominal wall was selected. The abdominal skin in a radius of about $10-15 \mathrm{~cm}$ was cleaned with betadine. Approximately $5-10 \mathrm{ml}$ of $2 \%$ xylocaine was infiltrated with a $23 \mathrm{G}$ needle at the selected site for aspiration. The whole tract of the CVS needle from the skin to the uterine fundus was infiltrated with the local anesthetic. $18 \mathrm{G}$ spinal needle was introduced from the same puncture site as local anesthesia, while standing on the right side of the patient. Thereafter, the USG probe was held in the right hand and the needle was maneuvered with the left hand. An important step in the procedure was to 
keep the needle tip visible at all times by sonography on monitor, after piercing the uterine wall, the needle was pushed with a jerky movement to enter the placenta in its longitudinal plane. The jerky forward push was helpful in avoiding any placental separation at the site of the needle entry. For an anterior placenta, the needle was kept in a horizontal direction while for a posterior placenta, the needle was kept vertically placed. While approaching a fundo-posterior placenta special care was required to avoid intestinal loops injury just above the fundus of uterus. If direct approach to complete posterior placenta was not possible, transamniotic approach was tried in a good numbers of cases where needle was passed through amniotic cavity by avoiding the fetus should not to be in line (trans amniotic approach keeping fetus in non-align and placenta in alien to needle and probe, Figure 1). Most important point in trans amniotic approach is keep proper alignment of needle with probe point. Entry point to uterine wall was sensitive so adequate infiltration of LA was essential. Spine needle rinsed with heparinized media was kept ready. The entry of needle into the placenta was appreciated by a loss of resistance. Once the needle was in the placenta (Figure 1), it was sufficiently advanced to leave at least 5-7 $\mathrm{mm}$ of the placental tissue ahead of the needle tip, then stylet was removed. A $10 \mathrm{CC}$ disposable syringe having 3-4 $\mathrm{ml}$ heparinized media attached to the spinal needle which was rinsed with heparinized media. Plunger of the syringe was pulled back to about $5 \mathrm{ml}$ mark to create a negative suction force and position is maintained by fingers of left hand. The aspiration syringe and needle in placental position were jiggled, to and fro movement done about 5-7 times, with simultaneous negative suction force created as mentioned. Disrupted villi were sucked into needle and than in syringe. The aspiration needle with syringe was removed with simultaneous negative suction force, and than whatever aspirated villi in syringe was taken in test tube or petri dish and adequate amount of grayish white placental villi confirmed for successful aspiration against light. In case of a poor yield of the sample, a second attempt may require, however third attempt was never tried. After removal of the spinal needle the puncture mark was sealed with a sterile elastic bandage. Post-aspiration sonography done to see the fetal wellbeing, and any placental separation or hematoma formation. The patients were allowed to go home after 2-3 hours with advice to take bed rest for 2-3 days. Prophylactic antibiotics with uterine relaxant given for five days.

\section{Outcome measures}

Outcome of the procedure in terms of genetic disorder diagnosis were recorded for each patient. Also, complications of procedure like hematoma, bleeding, fetal loss were also recorded. Also ease of procedure in terms of consultant's perception and reasons for choosing transamniotic approach were recorded.

\section{Statistical analysis}

The data was analyzed using Microsoft excel 2010 and results reported as actual frequencies, percentage, mean, $\mathrm{SD}$ as appropriate. For comparison of the routine and Tran amniotic approach for CVS procure related parameters and complications chi-square test was used and $p$ value less than 0.05 was considered significant.

\section{RESULTS}

A total of 2287 CVS procedures meeting inclusionexclusion criteria were included in the study. Mean age of patients were $27 \pm 3.3$ with range of (18-38 years) and average body weight of $56 \pm 5.4 \mathrm{~kg}$. As shown in Table 1 , in majority of patients $(1621,70.9 \%)$ the CVS procedure was performed between 12-14 weeks of gestation while in $28.07 \%$ (642) patients it was done at 11-12 weeks of gestation. Only for $1 \%$ (24) patients CVS was done between 14-15 weeks as patients were illiterate from remote places without proper routine antenatal care.

Table 1: Parameter related to mothers involved in the study (n=total - 2287).

\begin{tabular}{|l|l|}
\hline Parameter & No. $(\%)$ \\
\hline Maternal age & Range -20 -38 years \\
\hline Gestational age (in weeks) & \\
\hline $11-12$ & $642(28.07)$ \\
\hline $12-14$ & $1621(70.9)$ \\
\hline $14-15$ & $24(1.03)$ \\
\hline Total & $2287(100)$ \\
\hline $\begin{array}{l}\text { Maternal weight in kg } \\
\text { (Mean } \pm \text { SD) }\end{array}$ & $56 \pm 5.4$ \\
\hline Routine antenatal checkups & $2263(98.95)$ \\
\hline
\end{tabular}

Table 2: Position of placenta and physician's perception about selecting the CVS procedure.

\begin{tabular}{|lll|}
\hline $\begin{array}{l}\text { Position } \\
\text { of } \\
\text { placenta }\end{array}$ & $\begin{array}{l}\text { N } \\
(\%)\end{array}$ & $\begin{array}{l}\text { Physician's perception about } \\
\text { selecting the CVS procedure }\end{array}$ \\
\hline Anterior & $\begin{array}{l}709 \\
(31)\end{array}$ & $\begin{array}{l}\text { Most convenient placental } \\
\text { position for CVS }\end{array}$ \\
\hline $\begin{array}{l}\text { Fundo- } \\
\text { anterior }\end{array}$ & $\begin{array}{l}549 \\
(24)\end{array}$ & $\begin{array}{l}\text { Convenient placental position } \\
\text { for CVS }\end{array}$ \\
\hline $\begin{array}{l}\text { Fundo- } \\
\text { posterior }\end{array}$ & $\begin{array}{l}366 \\
(16)\end{array}$ & $\begin{array}{l}\text { Difficult by routine CVS but } \\
\text { may not require trans amniotic } \\
\text { (injury to intestine likely at } \\
\text { fundal part) }\end{array}$ \\
\hline $\begin{array}{l}\text { Complete } \\
\text { posterior }\end{array}$ & $\begin{array}{l}663 \\
(29)\end{array}$ & $\begin{array}{l}\text { Only way by trans amniotic } \\
\text { approach }\end{array}$ \\
\hline
\end{tabular}

Table 2 shows position of placenta and physician's perception about selecting CVS route. Out of total 2287 patients, $709(31 \%)$ and $549(24 \%)$ had anterior and fundoanterior placenta which is most suitable to access by routine transabdominal CVS. In 366 (16\%) patient's placenta was fundo-posterior which was accessed by routine CVS but with difficulty. 
Rest 663 (29\%) patients had complete posterior placenta which was not accessible with routine transabominal CVS.

Table 3: Analysis of CVS procedure related parameters: $(n=2287)$.

\begin{tabular}{|c|c|c|c|}
\hline Parameter & $\begin{array}{l}\text { Routine } \\
\text { CVS } \\
\text { No. }(\%)\end{array}$ & $\begin{array}{l}\text { Trans- } \\
\text { amniotic } \\
\text { approach } \\
\text { for CVS } \\
\text { No. }(\%)\end{array}$ & $\begin{array}{l}\mathbf{P} \\
\text { value* }\end{array}$ \\
\hline \multicolumn{4}{|c|}{ Attempts required for procedure } \\
\hline $\begin{array}{l}\text { Successful at } \\
\text { first attempt }\end{array}$ & $\begin{array}{l}1595 \\
(98.75)\end{array}$ & $663(100)$ & \multirow{3}{*}{0.2064} \\
\hline $\begin{array}{l}\text { Second attempt } \\
\text { required }\end{array}$ & $\begin{array}{l}29 \\
(1.25)\end{array}$ & 0 & \\
\hline Total & $\begin{array}{l}1624 \\
(100)\end{array}$ & 663 (100) & \\
\hline \multicolumn{4}{|c|}{ Amount of sample received } \\
\hline $\begin{array}{l}\text { Very good } \\
(>25 \mathrm{~g})\end{array}$ & $\begin{array}{l}1830 \\
(80)\end{array}$ & $\begin{array}{l}612 \\
(92.30)\end{array}$ & \multirow{4}{*}{0.1185} \\
\hline Good (10-25 g) & $\begin{array}{l}448 \\
(19.6)\end{array}$ & 49 (7.39) & \\
\hline $\begin{array}{l}\text { Inadequate }(<10 \\
\mathrm{g})\end{array}$ & $9(0.04)$ & $2(0.30)$ & \\
\hline Total & $\begin{array}{l}1624 \\
(100)\end{array}$ & $663(100)$ & \\
\hline
\end{tabular}

In these $29 \%$ of cases, routinely CVS procedures were postponed by most physicians leading to delay in diagnosis of genetic disorders. With novel approach of transabdominal-trans-aminotic route, the CVS was successfully completed at this study center. In skilled hands, this novel approach can help in early prenatal diagnosis of genetic disorders. The factors associated with a difficult aspiration in posterior complete placenta, were obesity, retroverted uterus, scar over abdomen, fibroids, and thin placental plate as per consultant's perception and reason for opting for transabdominal trans amniotic approach. Above all factors were not intervening for anterior or anterior fundal placenta.

Procedure related parameters are shown in Table 3. Aspiration was successful by routine CVS approach in first attempt in $1595(98.75 \%)$ patients while second attempt was required in rest $29(1.25 \%)$ patients (because of block needle or frank blood aspiration). On other hand by Transamniotic approach CVS was successfully completed in all $663(100 \%)$ patients. Number of attempts required to get the desired amount of sample was not statistically significant ( $\mathrm{p}>0.05)$ by both the methods of CVS. In 1830 $(80 \%)$ patients, the sample yield was very good (>25 mg), in 448 patients $(19.6 \%)$ it was good and adequate and in rest $9(0.04 \%)$ patients it was inadequate by routine transabdominal CVS. On other hand 612 patients had very good yield and only 2 patients had inadequate by transamniotic CVS. Amount received for sample was also not statistically significant by both methods $(\mathrm{p}>0.05)$. There were 11 patients in whom the aspiration was postponed or amniocentesis offered. Reasons for postponement were suspected cardiac anomalies (two fetuses), 2 patient were uncooperative patients (two patients) and having poor yield (seven patients). Out of these 11 patients, 9 were called for amniocentesis at 17 weeks. The overall success rate was $99 \%$.

Table 4: Complications related to the procedure by both CVS techniques: $(n=2287)$.

\begin{tabular}{|c|c|c|c|c|}
\hline Complications & $\begin{array}{l}\text { Routine CVS } \\
\text { No. }(\%)\end{array}$ & $\begin{array}{l}\text { Trans-amniotic CVS } \\
\text { No. }(\%)\end{array}$ & P value & Action taken/treatment given \\
\hline $\begin{array}{l}\text { Pain and } \\
\text { discomfort }\end{array}$ & $1295(79.74)$ & $52(78.58)$ & 0.86 & $\begin{array}{l}\text { Relived within a day. Analgesic } \\
\text { prescribed in } 10 \% \text { of patients only }\end{array}$ \\
\hline $\begin{array}{l}\text { Hematoma } \\
\text { formation }\end{array}$ & $10(0.62)$ & $2(0.30)$ & 0.98 & $\begin{array}{l}\text { Ask for follow up scan \& all were } \\
\text { normal }\end{array}$ \\
\hline Spotting/Bleeding & $24(1.48)$ & $6(0.90)$ & 0.95 & Relived of symptoms within $2-3$ days \\
\hline Abortion & $13(0.80)$ & $4(0.60)$ & 0.99 & $\begin{array}{l}\text { Occurred within } 10-15 \text { days and } \\
\text { complete care given for it }\end{array}$ \\
\hline Infection & 0 & 0 & 0 & - \\
\hline Oligohydramnios & $2(0.12)$ & $1(0.1)$ & 0.99 & All three were counsel for termination. \\
\hline $\begin{array}{l}\text { Fetal cardiac } \\
\text { pulsation lost just } \\
\text { after procedure }\end{array}$ & $1(0.06)$ & 0 & 0.99 & Counsel for termination of pregnancy \\
\hline
\end{tabular}

Complications following CVS has been shown in Table 4. No statistically significant difference was found for developing complications by both the methods ( $p>0.05)$.
Most patients felt pain and discomfort lasting up to 36 hours after the procedure by routine transabdominal or transamniotic CVS that was relieved by using simple analgesics. 


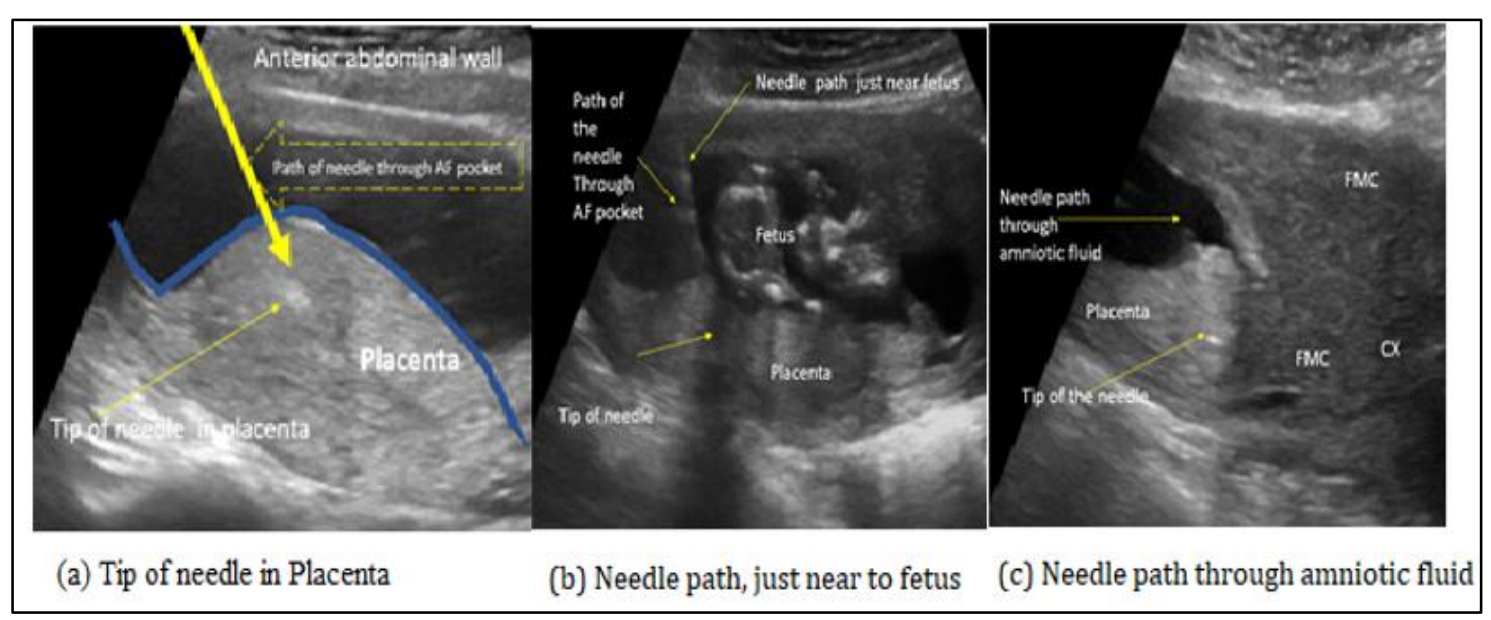

Figure 1: Sonographic pictures of the CVS procedure of trans-amniotic approach (how to avoid fetus while entry through amniotic cavity).

Hematoma formation was seen in $10(0.62 \%)$ and $2(0.3 \%)$ of patients in transabdominal and transamniotic CVS respectively $(\mathrm{p}>0.05)$. Out of total 2287 procedures, 17 $(0.74 \%)$ abortions has taken place in this study. Thirteen patients $(0.80 \%)$ had abortion in transabdominal and 4 $(0.60 \%)$ had abortion by trans amniotic route CVS with no statistically significant difference among them $(p>0.05)$. No case of post procedure infection was observed.

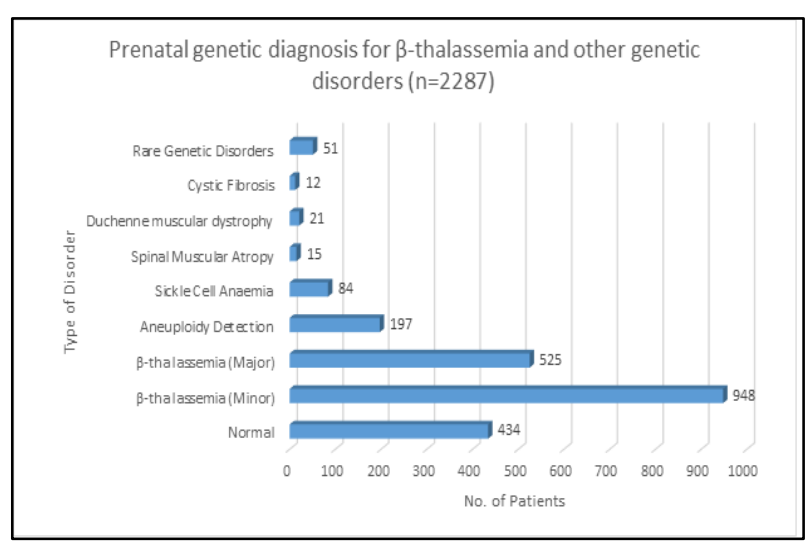

Figure 2: Prenatal diagnosis of genetic disorders of the processed samples $(n=2287)$.

After completing the CVS procedures and laboratory analysis, most common genetic disorders were found to be thalassemia major in $948(41.45 \%)$ patients, thalassemia minor in $525(22.96 \%)$ followed by aneuploidy detected in $197(8.61 \%)$ patients as shown in Figure 2.

\section{DISCUSSION}

Most women wish to be reassured that their unborn baby is healthy. Inevitably, any screening programme that aims to provide such reassurance will cause anxiety while waiting for the test results. The additional problems are 'false positive' screening test results (maternal serum screening and ultrasound) and lack of therapeutic options for chromosomal abnormalities. Therefore, the aim is to select screening and diagnostic tests that are both accurate and safe, and can be done early in pregnancy to allow the choice of termination of pregnancy. Ultrasound is the method of choice for detection of anatomical problems (example- absent kidneys, spina bifida), but provides no information on the genetic constitution of a fetus. ${ }^{13}$ Maternal serum screening, alone or in combination with ultrasound, is often used to identify fetuses at risk of Down syndrome, but the definitive chromosomal diagnosis can only be made from fetal cells. ${ }^{14}$

The biopsy or aspiration of chorionic villi by the vaginal route yields fetal cells, several of which are in the process of dividing and can be analyzed during the hours following the procedure. There is a risk of miscarriage and maternal cell contamination of the specimen thus leading a number of clinicians to abandon this procedure done before the 12th week of pregnancy. Reduction limb defects have been reported if the CVS is done towards the end of the first trimester. ${ }^{15-17}$ In special circumstances when the risk of genetic disease is high as for instance in hereditary metabolic diseases or if one of the parents is carrier of a balanced chromosomal translocation, this technique has the advantage of reaching a diagnosis around the 11 th or 12 th week of gestation. ${ }^{18}$

Prenatal diagnosis through early fetal sampling has played a pivotal role in the prevention of thalassemia and genetic disorders. Ultrasound guidance adds to the safety for the fetus as well as the mother. Chorionic villus sampling was introduced in the early $80 \mathrm{~s}$ and since then it has given a new dimension to prenatal diagnosis. Procedure can be done earlier than amniocentesis, in this study majority of the procedure were done between 12-14 weeks. At this stage, the placenta is of adequate size that can be sampled without much difficulty. The best time for CVS appears to be around 12-14 weeks. Earlier aspiration is difficult due to thin placental plate, however earlier doing CVS will always be helpful to terminate abnormal fetus. The CVS is done either trans abdominally or through the trans-cervical route, disadvantage of the trans-cervical route is the 
possibility of transmitting infection from the contaminated cervical canal. The trans-abdominal route has an obvious advantage of mechanical similarity to amniocentesis that makes CVS easier and familiar to perform. ${ }^{12}$

Although there are limited data comparing trans cervical and transabdominal CVS, there does not appear to be a significant difference in fetal loss rates between the two approaches. ${ }^{19}$ The primary advantage of CVS over amniocentesis is that results are available earlier in pregnancy, which provides reassurance for parents when results are normal and, when results are abnormal, may allow for earlier and safer pregnancy termination. In addition, for patients in whom specialized direct DNA testing is to be performed, CVS samples are more cellular and provide larger amounts of DNA for direct analysis, allowing a more rapid turnaround time. ${ }^{20}$

In this study, practically all positions of placenta were sampled through the transabdominal route without much difficulty that makes it the most feasible choice for use in routine practice. However, for complete posterior placenta people are afraid for trans-amniotic approach, in our study we have approach posterior placenta by our specific technique that is in line placenta and avoid fetal alinement with probe and needle as shown in three different images of sonography. This novel approach is found to be safe and effective in skilled hands.

The choice of needle for CVS may vary from a simple 18 $\mathrm{G}$ spinal needle to the co-axial chorion biopsy needles. The latter is costlier and availability is problem. Due to higher gauze chance of placental disruption and separation is higher with higher pain to mother. Irrespective of position of placenta, transabdominal route is comfortable by most physicians. Technical limitation is only FMC, fibroids or retro- verted uterus, multiple scars and high BMI. TAS has less infection rate, abortion rate and failure rate also less in comparison to trans cervical which has abortion rate upto $10 \%$ as per literatures. Routinely we select $1.2 \times 90 \mathrm{~mm} 18$ $\mathrm{G}$ BD needle. In cases of higher BMI or increased depth of placenta we have selected $15 \mathrm{~cm}$ long aspiration needle. Single and once prick is best for almost $99.9 \%$ of patients.

CVS is a safe procedure in experienced hands. Mild and transient post procedure pain due to uterine cramps, not more than that felt after amniocentesis, is common. Bacterial contamination is a rare but serious complication that is best avoided by taking utmost care of sterilization. In fundal placenta usually the junction where fundus of uterus is abutting to maternal intestine and while approaching placenta with needle injury to intestinal loops may take place (taking care regarding we have never observed such type of problems). The overall rate of fetal loss is $17 / 2287(0.74 \%)$ which is comparable to other studies. $^{21,22}$

Overall, this study has generated a huge data of CVS procedures for different types of placental positions and introduced a novel method for CVS i.e., trans-amniotic route. Generally, around $30 \%$ of patients having complete posterior placenta are postponed for amniocentesis for prenatal genetic diagnosis. Trans-amniotic CVS can be safe and effective method for early diagnosis of genetic disorders in such patients. Only limitation of the study is that the data are from single center. Further multi-centric studies are needed in this direction to make the transamniotic approach of CVS more useful for patients.

\section{CONCLUSION}

Ultrasound guided transabdominal CVS is a useful outdoor procedure for fetal sampling and prenatal diagnosis. It can play an important role in the prevention of genetic disorders that are otherwise incurable. A placenta in almost any position can be approached without much difficulty. The procedure is also safe for the mother as well as the fetus. For complete posterior placenta trans amniotic approach can be safely used without any complications.

\section{ACKNOWLEDGEMENTS}

Authors are thankful to Red Cross Society of Gujarat, India for creating awareness regarding thalassemia \& providing monitory support to poor patients for getting screening procedures done.

Funding: No funding sources

Conflict of interest: None declared

Ethical approval: The study was approved by the Institutional Ethics Committee

\section{REFERENCES}

1. Kazal RK, Chowdhury SA, Parveen T, Pervin HH, Noor F, Akhter N. Chorionic Villus Sampling (CVS) for Prenatal Diagnosis of Genetic Disorders in Bangladesh. Bangladesh J Obstet Gynaecol. 2016;31(2):63-9.

2. Ahmed S. Transabdominal chorionic villus sampling (CVS) for prenatal diagnosis of genetic disorders. J Coll Physicians Surg Pak. 2006;16(3):204-7.

3. Jackson LG, Zachary JM, Fowler SE, Desnick RJ, Golbus MS, Ledbetter DH et al. A Randomized comparision of Transcervical and Transabdominal Chorionic-Villus Sampling. N Engl J Med. 1992;327(9):594-8.

4. Kazal RK, Chowdhury SA, Mirza TT, Pervin HH, Noor F, Chakma B et al. Feasibility and Safety of Chorionic Villus Sampling (CVS) for Prenatal Diagnosis of Thalassemia in Bangladesh. Mymensingh Med J. 2018;27(3):578-84.

5. Alfirevic Z, Navaratnam $K$, Mujezinovic $F$. Amniocentesis and chorionic villus sampling for prenatal diagnosis. Cochrane Database of Systematic Reviews. 2017;9:CD003252.

6. Fetal sex prediction by sex chromatin of chorionic cells during early pregnancy. Chinese Medical Journal. 1975;1(2):117-26. 
7. Alfirevic Z, von Dadelszen P. Instruments for chorionic villus sampling for prenatal diagnosis. Cochrane Database of Systematic Reviews. 2003(1):20-4.

8. Blumenfeld YJ, Chueh J. Chorionic villus sampling: technique and training. Curr Opin Obstet Gynecol. 2010;22(2):146-51.

9. Choudry A, Masood S, Ahmed S. Feasibility and safety of trans abdominal chorionic villus sampling. J Ayub Med Coll Abbottabad JAMC. 2012;24(1):3843.

10. Cavoretto P, Dallagiovanna C, Spagnolo D, Candiani M. Percutaneous transvesical chorionic villus sampling: A safe alternative method for difficult procedures? Ultrasound in Obstetrics and Gynecology. 2014;44(1):115116.

11. Soothill PW, Finning K, Latham T, Wreford-Bush T, Ford J, Daniels G. Use of cffDNA to avoid administration of anti-D to pregnant women when the fetus is RhD-negative: implementation in the NHS. BJOG. 2015;122:1682-6.

12. Ahmed $\mathrm{S}$. Transabdominal chorionic villus sampling (CVS) for prenatal diagnosis of genetic disorders. J Coll Physicians Surg Pak. 2006;16(3):204-7.

13. Goncalves LF, Nien JK, Espinoza J. What does twodimensional imaging add to 3- and 4-dimensional obstetric ultrasonography? J Ultrasound Med. 2006;25:691-9.

14. Wald NJ, Cuckle HS, Densem JW, Nanchahal K, Royston P, Chard T et al. Maternal serum screening for Down's syndrome in early pregnancy. BMJ. 1988;297(6653):883-7.

15. Green JJ, Hobbins JC. Abdominal ultrasound examination of the firsttrimester fetus. Am J Obstet Gynecol. 1988;159:165-75.
16. Grande M, Arigita M, Borobio V. First-trimester detection of structural abnormalities and the role of aneuploidy markers. Ultrasound Obstet Gynecol. 2012;39(2):157-63.

17. Abu-Rustum RS, Daou L, Abu-Rustum SE. Role of first-trimester sonography in the diagnosis of aneuploidy and structural fetal anomalies. J Ultrasound Med. 2010;29(10):1445-52.

18. Souka AP, Pilalis A, Kavalakis Y. Assessment of fetal anatomy at the 11-14-week ultrasound examination. Ultrasound Obstet Gynecol. 2004;24(7):730-4.

19. Cavoretto P, Dallagiovanna C, Spagnolo D, Candiani M. Percutaneous transvesical chorionic villus sampling: a safe alternative method for difficult procedures? Ultrasound Obstet Gynecol. 2014;44:115-8.

20. Odibo AO, Dicke JM, Gray DL, Obrele B, Stamilio DM, Macones GA et al. Evaluating the rate and risk factors for fetal loss after chorionic villus sampling. Obstet Gynecol. 2008;112:813-9.

21. Tabor A, Vestergaard CHF, Lidegaard $\varnothing$. Fetal loss rate after chorionic villus sampling and amniocentesis: an 11-year national registry study. Ultrasound Obstet Gynecol. 2009;34:19-24.

22. Tabor A, Alfirevic Z. Update on procedure-related risks for prenatal diagnosis techniques. Fetal Diagn Ther. 2010;27:1-7.

Cite this article as: Patel BI, Patel S, Patel N.

Exclusive transabdominal trans-amniotic approach for chorionic villus sampling in posterior placenta: a novel approach for prenatal diagnosis of genetic disorders. Int J Reprod Contracept Obstet Gynecol 2021; 10:3737-43. 